\title{
THREE OPTIONS ARE BETTER THAN TWO: COMPENSATORY NATURE OF DIFFERENT POLLINATION MODES IN SALIX CAPREA L.
}

\author{
Kazuharu Ohashi, ${ }^{1,2, *}$, Andreas Jürgens ${ }^{2}$ \\ ${ }^{1}$ Graduate School of Life and Environmental Sciences, University of Tsukuba, Tsukuba, Ibaraki 305-8572, Japan \\ ${ }^{2}$ Chemical Plant Ecology, Technische Universität Darmstadt, Department of Biology, Schnittspahnstrasse 10, 64287 \\ Darmstadt, Germany
}

Journal of Pollination Ecology, 28(7), 2021, pp 75-90

DOI: $10.26786 / 1920-$

$7603(2021) 627$

Received 29 September 2020, accepted 4 December 2021

*Corresponding author:

kohashi@biol.tsukuba.ac.jp

\begin{abstract}
Mixed pollination systems have been reported for many angiosperms. Here, we report on a dioecious willow, Salix caprea L., which employs three pollination modes, namely pollination by wind, nocturnal moths, and diurnal bees. In four field populations of $S$. caprea in Germany, we addressed the following questions: (a) How are the pollination modes affected by local mate availability? (b) What is the contribution of each pollination mode to seed set? (c) How does flower opening time affect pollination? We compared seed set among seven pollination treatments (wind pollination, diurnal pollination, nocturnal pollination, natural pollination, apomictic reproduction, daytime/night-time artificial pollination). Pollen limitation was observed across populations. On the other hand, limitations in mate availability affected the pollination modes differently. Insect pollination outperformed wind pollination in situations where nearby males were few or all positioned in the same direction from the females. The contribution of nocturnal moths was lower than that of the other pollen vectors. However, moth pollination worked complementarily with bee pollination in compensating for the lack of wind pollination. Furthermore, we found that the onset of flower anthesis peaked at sunset, and that cold night temperatures had no negative effect on seed set or pollen viability. Thus, nocturnal anthesis and prior pollination by moths may minimize male fitness loss due to pollen collection and grooming by bees. We suggest that $S$. caprea maximizes its fitness by combining multiple pollination modes that work in different environmental conditions, while optimizing the anthesis so that more pollen would be delivered to stigmas.
\end{abstract}

Keywords-Adaptive generalization, compensation, flower opening time, local mate availability, mixed pollination systems, Salix caprea

\section{INTRODUCTION}

The evolution of flowers has often been considered to increase specificity for the most effective pollen vectors (Grant \& Grant 1965; Stebbins 1970; Johnson \& Steiner 2000), while sometimes excluding other, less effective ones (Thomson et al. 2000; Johnson et al. 2006). It has recently been recognized, however, that some flowers simultaneously employ distinct pollen vectors, which are referred to as mixed or generalized pollination systems. Some species exhibit a mixture of animal and wind pollination, called ambophily (Duan et al. 2009; Costa \& Machado 2012). Others accommodate diverse groups of animal pollinators, often including both diurnal and nocturnal ones (Muchhala et al. 2008; Amorim et al. 2013; Dötterl et al. 2012; Dellinger et al. 2019). Mixed pollination systems have often been thought to provide reproductive assurance when the availability of specific vectors varies spatially or temporally (Goodwillie 1999; MarténRodríguez \& Fenster 2010; Gong et al. 2016).

Despite this increasing recognition of the importance of mixed-pollination systems, several important questions have not been fully explored to date. First, which types of pollination modes are likely to be combined in a given mixed pollination system? One possibility would be that selection for 
reproductive assurance favors the combination of modes that are differently affected by environmental factors so that they compensate for each other's disadvantages. For a mixedpollination system to have an adaptive value, different modes should have different environments in which they work better, and thus the deficiency of one mode should be able to be compensated by another. Only when such a condition is met, different modes can become complementary in the long run, i.e., have an additive effect on the long-term reproductive success, even if they are temporarily or locally redundant, i.e., substitutable at a particular time or place. For example, wind and animal pollination may be differently affected by precipitation (Rech et al. 2016). Thus, while high precipitation or humidity has been suggested to make pollen grains heavier or cause them to clump, thereby reducing dispersal distance by wind (Niklas 1985), the same microclimatic conditions may increase photosynthetic productivity and support more nectar production for animal pollination (Rech et al. 2016). Consequently, a combination of wind and animal pollination could mitigate the negative effects of fluctuations in annual rainfall. From a conservation point of view, it is an important question whether different vectors in a particular pollination system are complementary (additive) or redundant (substitutable), because compensation for missing vectors is more likely to occur when vectors are redundant than complementary (see Fleming et al. 2001). However, so far it has not been tested in a mixedpollination system whether different vectors compensate each other across heterogeneous environments so that they could increase the longterm reproductive success.

Second, how do flowers mitigate the potential conflicts among fitness contributions of multiple pollen vectors? In particular, pollen vectors may differ greatly in the proportion of pollen removed from anthers that is delivered onto stigmas (Thomson et al. 2000; Muchhala \& Thomson 2010). When the number of pollen grains are limited and removal by one vector reduces the amount of pollen available to the other vectors, this may cause a problem. That is, the use of multiple pollen vectors may not lead to an increase in male fitness of a flower, because inefficient vectors waste pollen that could otherwise be delivered to stigmas by more efficient vectors (Thomson \& Thomson 1992; Thomson et al. 2000). This could be a common problem in mixed-pollination systems that often have flowers with exposed anthers.

Salix caprea L. is a dioecious shrub or small tree that is known to have a mixed-pollination system employing three different vectors: wind, diurnal bees, and nocturnal moths (Jürgens et al. 2014). Flowers are arranged in brush-like inflorescences (catkins), whereby male catkins offer pollen and nectar as a reward, and female catkins offer nectar only (Kay 1985). The size of pollen grains is intermediate (15-20 $\mu \mathrm{m}$ in diameter) among species with biotic pollination (Culley et al. 2002), which would be suitable for transport by both wind and insects. Moreover, the flowers change their floral scent profiles between day and night, suggesting that they specifically attract bees during the daytime and moths during the nighttime (Jürgens et al. 2014). It has been shown that the production of scent chemicals is especially important in Salix flowers because they have no conspicuous visual cues except yellow pollen (Dötterl et al. 2014; Jürgens et al. 2014).

The mixed pollination system in the early blooming, dioecious $S$. caprea can be viewed as an adaptation to ensure reproduction in a relatively poor mating environment (Culley et al. 2002). However, it is not well known whether and how the three pollination modes differ in their contribution to plant fitness and if they compensate each other. It is also unclear how flowers of S. caprea may mitigate potential conflicts or tradeoffs among the three pollination modes. One could argue that phenotypic tradeoffs are trivial in this species, because the brush-like catkins would allow any type of insect to contact anthers and stigmas, the medium-sized pollen would maximize total pollen transport via wind and insects, and the diel pattern of fragrance would skirt around the fitness valley created by distinct odor preferences of bees and moths. On the other hand, different pollen transfer efficiencies of vectors could cause a reduction of male fitness due to inefficient pollen transport. For example, exposed anthers in S. caprea may increase pollen removal and, in turn, pollen losses due to grooming by bees (Harder \& Thomson 1989; Miyake \& Yahara 1998). In contrast, moths have no dietary interest in pollen, nor do they exhibit 
grooming behaviour while foraging. Thus, bees may be less efficient pollen vectors than moths for $S$. caprea. Considering that bees visit $S$. caprea approximately ten times more frequently than moths (Jürgens et al. 2014), they probably waste pollen that could otherwise be transferred more efficiently by moths. In such situations, it would be advantageous for male flowers of $S$. caprea to open at dusk, unless cold temperatures at night have a negative effect on seed set or pollen viability.

Here, we conducted field experiments and observations in four native populations of $S$. caprea in Germany to explore the possibility of compensatory relationships among different pollination modes, as well as of an optimized timing of anthesis to minimize pollen wastage. We first compared the relationships between seed production and local mate availability of individual females among diurnal, nocturnal, and wind pollination, as well as among populations, in order to address how different modes are limited by spatial heterogeneity of the environment. Based on the results from different types of bagging treatments, we asked whether the three pollination modes compensate for each other's limitations, and how the simultaneous use of three modes could help to ensure reproduction in S. caprea. Moreover, we investigated if $S$. caprea maximizes male fitness by opening their flowers at dusk so that they prioritize the visits by nocturnal moths and minimize pollen wastage by diurnal bees. Finally, we tested if the cold temperatures at night had a negative effect on nocturnal pollination, both in terms of pollen viability and ovule fertilization.

\section{MATERIALS AND METHODS}

\section{STUDY SITES}

We studied four populations of S. caprea, all of which were located in Odenwald, Hessen, Germany: Heubach (hereafter, HB; 49050'25" N, 856'55" E), (ii) Ohlebach (hereafter, OB; 4950'53" N, 856'05" E), (iii) Wiebelsbach (hereafter, WB; 4950'00" N, 856'35" E), and (iv) MümlingGrumbach (hereafter, MG; 4946'05" N, 85ㅗ'28" E). Each population was ca. $1.0-7.5 \mathrm{~km}$ apart from its nearest population. Although a genetic study suggests high levels of gene flow among distant populations of $S$. caprea in Ireland (Perdereau et al. 2014), our data suggests that such long-distance pollen flow between populations kilometers apart might be an extremely rare event at least in our study sites (see results).

$\mathrm{HB}$ was located at the edge of ca. 1.5 hectares of wetland and was surrounded by farmland and a road. OB was located within ca. 6.5 hectares of semi-grassland where individuals were distributed along a stream. WB was located within ca. 12 hectares of mowed field in front of a train station, where individuals were distributed along two lines of streams. MG was located within a forest reserve, where individuals were distributed within an area of 22 hectares along a small hikepath. The former three populations, i.e., $\mathrm{HB}, \mathrm{OB}$, and $\mathrm{WB}$, were open stands next to streams or wetland, which is a typical habitat for $S$. caprea. The last population, i.e., MG, was a closed stand distant from streams, where all females were surrounded by tall conifer and beech trees except on the sides facing the forest path. For the spatial distribution of $S$. caprea trees and the surrounding vegetation, see satellite images in Appendix I.

\section{POLLINATION EXPERIMENTS}

During April-May in 2018, we chose 20 female trees for pollination experiments according to their accessibility (HB: two trees; OB: three trees; WB: six trees; MG: nine trees), whereas the coordinates of all male trees within a 600-m radius were recoded using Garmin eTrex 30x handheld GPS with an accuracy of less than two meters (HB: 14 trees; OB: four trees; WB: 14 trees; MG: five trees). We then randomly chose 332 catkins (HB: 26 catkins; OB: 42 catkins; WB: 103 catkins; MG: 161 catkins) and assigned one of the following seven treatments to each of them, being careful not to concentrate one treatment on a particular plant: (i) "wind pollination", in which catkins were covered with organza mesh bags before anthesis without further manipulation, (ii) "diurnal pollination", in which catkins were covered with paraffin paper bags for fruit protection (SHIBATAYA KAKOHSHI, Co., Ltd., Niigata) during the nighttime and were exposed to insects and wind only during the daytime, (iii) "nocturnal pollination", in which catkins were paper bagged during the daytime and were exposed to insects and wind only during the night-time, (iv) "natural pollination", in which catkins were exposed to insect visitors throughout anthesis (positive control), (v) "apomictic reproduction", in which catkins were paper bagged before anthesis without 
further manipulation (negative control), (vi) "daytime hand pollination", in which catkins were paper bagged throughout anthesis and handpollinated once during the daytime (only in $\mathrm{OB}$ and WB), and (vii) "night-time hand pollination", in which catkins were paper bagged throughout anthesis and hand-pollinated once during the night-time (only in $\mathrm{OB}$ and WB). In hand pollination treatments, pollen collected from freshly bloomed flowers on one or two male trees were used for siring each female. These fathers were chosen haphazardly within the vicinity of the focal female (mating distance $=4.8-195 \mathrm{~m}$ ). For each female, the same fathers were used in daytime and night-time hand pollination. After anthesis, all catkins were mesh bagged until the fruits (capsules) matured and started to dehisce. Catkins with mature or dehisced capsules were harvested accordingly. All the capsules and mature seeds in each catkin were then counted.

We also assessed the effects of pollination treatments on seed quality in terms of germination ability. Mature seeds from 1-5 catkins per pollination treatment (diurnal/nocturnal/wind/ natural/daytime hand/night-time hand) were collected from each of the 20 females, and divided into one or a few groups of 50 seeds (mean $\pm \mathrm{SD}=$ $38.3 \pm 18.7, N=61$ ). Each group of seeds was sown on the top of a double layer of filter paper moistened with distilled water in a $90 \times 15 \mathrm{~mm}$ Petri dish. The Petri dishes were arranged on a table in a randomized design, which was set in a laboratory room $\left(23-24^{\circ} \mathrm{C}\right)$ so that the sunlight from the window would be evenly distributed (ca. 900 lux on sunny days). Distilled water was added accordingly to keep the filter papers moist. The germination of $S$. caprea took place in light conditions soon after watering without any prior treatment, and all viable seeds germinated within several days (Popova et al. 2012). We counted the number of sprouts that both cotyledons were unfolded by day six as germinated. To avoid possible decline of germination ability, all the tests were completed within one month from the day of harvest.

During the pollination experiments, the only co-flowering Salix congener in the study areas was S. purpurea L. We observed a few blooming individuals of S. purpurea in OB and MG, but hand pollination with pollen of this species yielded no seed in $S$. caprea ( $N=10$ catkins). Therefore, we assume that the effects of interspecific hybridization on seed set and germination ability was minimal in our experiments.

\section{ONSET OF ANTHESIS}

We determined the onset of anthesis for five haphazardly chosen catkins on three male trees by photographing every 30 minutes with the timelapse function of Pentax Optio W90 camera. We covered the camera flash with a layer of sunshade film for car windows $(30 \%$ visible light transmission) over the green plastic sheet (memorization sheet, NIHON PARL KAKOH Co., Ltd., Osaka) to minimize the effects of the flashlight on the circadian clock of plants. The branches with the focal catkins were fixed with wire to sticks inserted into the ground so that they would not sway in the wind. After the season, we counted the number of newly opened flowers within the field of view of each time-lapse image. Because each male flower has a pair of anthers, we recorded an additional projection of two anthers as the opening of a new flower.

\section{EFFECTS OF TEMPERATURE ON POLLEN LONGEVITY}

Pollen longevity in different temperature conditions was evaluated by estimating viability using the MTT test for presence of dehydrogenases in pollen (Rodriguez-Riano \& Dafni 2000). We collected 14 catkins that just had begun to dehisce from six male trees (four in $\mathrm{WB}$, one in $\mathrm{MG}$, and one from the campus of the Technical University Darmstadt). A small amount of pollen from each catkin was scattered on a slide glass. $10 \mu \mathrm{l}$ of MTT (3-4.5 Dimethylthiazol-2-yl-2.5-diphenyltetrazolium bromide, Sigma M-2128) in 5\% (w/v) sucrose solution was dropped onto these grains, gently stirred, and placed on a moderately warmed metal plate for two minutes. Then $5 \mu l$ of MTT was added and a cover glass was placed over it. After another minute, the stained pollen was examined under a microscope. For each prepared slide, we counted all the viable and inviable grains within a field of view three times, being careful not to observe the same field more than once. After the first staining, the remaining pollen from each catkin was enclosed in folded paper and stored either in room temperature or at $-20^{\circ} \mathrm{C}$ in a freezer. Then we repeated the same staining procedure at $12,24,48,72$, and $96 \mathrm{~h}$ later, respectively. 


\section{STATISTICAL ANALYSIS}

Using the coordinates we recorded for each tree, we calculated the distance of individual males from each focal female. We also calculated how diverse the positions of surrounding males were relative to the focal female in terms of direction from that female, and referred to it as "directional diversity of nearby males". We considered only males within a $100 \mathrm{~m}$ radius of the focal female as its "nearby" ones, based on the observation that wind pollination yielded few or no seed when females were more than $100 \mathrm{~m}$ away from males (Fig. 3A). The directional diversity was calculated by subtracting the mean resultant length from one. The mean resultant length is the most commonly used measure of the concentration of circular data (Pewsey et al. 2013). To calculate a mean resultant length, we measured the directions (angles) of the nearby males relative to the focal female on a $0^{\circ}$ $360^{\circ}$ scale, counterclockwise from the east direction. For each female, we represented the directions of males as unit vectors and calculated the length of the resultant (i.e., combined) vector. Then we calculated the mean resultant length (MRL) as the ratio of the observed length of the resultant vector to the maximum possible length of resultant vector of the same sample size which is obtained when all the males are located in the same direction from the female. For actual computation of MRL, we used the rho.circular function in the $\mathrm{R}$ package "circular" (Pewsey et al. 2013). Finally, we calculated "directional diversity of nearby males" as (1 - MRL). A value close to zero indicates that the nearby males are clustered in a certain direction from the focal female. When the nearby males are spread in various directions from the focal female, the directional diversity will take a value near one.

To determine whether the proximity of nearby males and their distribution around females affected the three pollination modes differently, we fitted a generalized linear-mixed model (GLMM) to each of three pollination treatments (wind/diurnal/nocturnal), using a logarithmic link function and a Poisson error distribution. The number of mature seeds per capsule and the number of capsules per catkin were used as the response variable and an offset, respectively. We considered the distance to the nearest male and the directional diversity of nearby males as fixed effects, and population and plant as nested random effects. In practice, the effect of population was negligible for some pollination treatments (the among-population variance in \% seed set was estimated as almost zero; Table 1). In such cases, we incorporated only plant as a random effect, which was more appropriate when the sample size was small.

We also compared seed set per capsule among five pollination treatments (wind/diurnal/ nocturnal/ natural/apomictic reproduction) by fitting a GLMM with a logarithmic link function and a Poisson error distribution. We treated the number of mature seeds per capsule as the response variable and the number of capsules in

Table 1. Effects of local mate availability on seed set of Salix caprea in different pollination treatments. Fixed effects were estimated in each GLMM for each treatment. A type II Wald chi-square test was performed for each estimate. SDs for the random effects were shown in the rightmost column as heuristic measures of variance among plants or populations compared to the fixed effects.

\begin{tabular}{|c|c|c|c|c|c|}
\hline Treatment & Fixed effect & Estimates & $\chi^{2}$ & $P$ & SD for random effect \\
\hline \multicolumn{6}{|l|}{ Wind } \\
\hline & Distance to the nearest male & $-0,0086$ & 12,7 & $<0.001$ & Plant: 0.72 \\
\hline & Directional diversity of nearby males & 0,82 & 125467 & $<0.0001$ & Population: 2.40 \\
\hline \multicolumn{6}{|l|}{ Diurnal } \\
\hline & Distance to the nearest male & $-0,01$ & 10,9 & $<0.001$ & Plant: 1.79 \\
\hline & Directional diversity of nearby males & $-2,31$ & 1,2 & 0,28 & Population: 0.000044 \\
\hline \multicolumn{6}{|l|}{ Nocturnal } \\
\hline & Distance to the nearest male & $-0,0054$ & 2,2 & 0,14 & Plant: 1.65 \\
\hline & Directional diversity of nearby males & 0,18 & 0,01 & 0,94 & Population: 0 \\
\hline
\end{tabular}



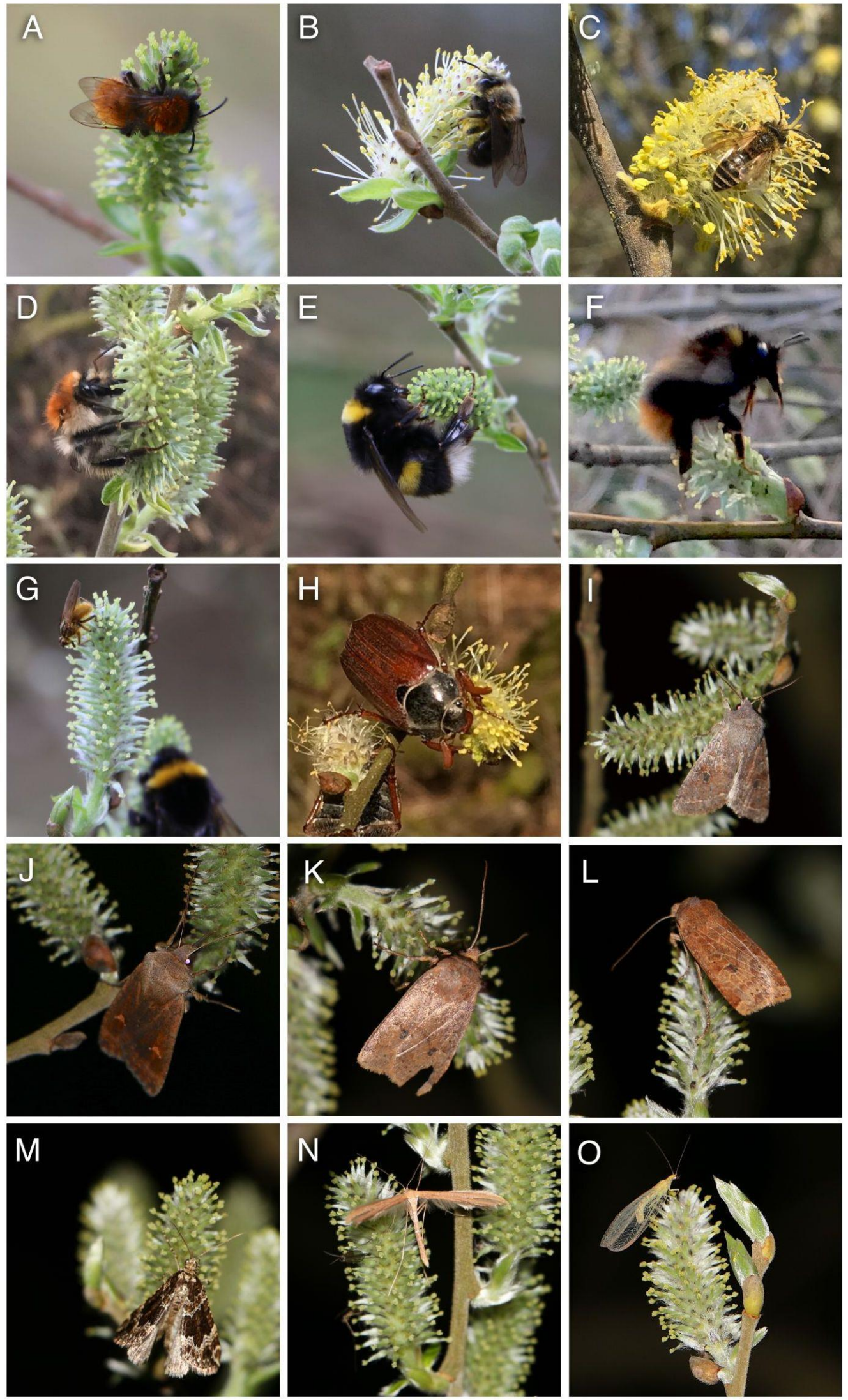

Figure 1. Flower visitors of Salix caprea: A: Andrena fulva, B: A. vaga, C: Colletes cunicularius, D: Bombus pascuorum (queen), E: B. lucorum (queen), F: B. pratorum (queen), G: Scathophaga stercoraria, H: Melolontha melolontha, I: Orthosia incerta, J: Eupsilia transversa, K: Conistra vaccinii, L: Agrochola circellaris, M: Epirrhoe alternata, N: Pterophoridae sp., O: Chrysoperla carnea. All photos taken by K. Ohashi ( $\mathrm{A}-\mathrm{H}=$ diurnal, $\mathrm{I}-\mathrm{O}=$ nocturnal). 
each catkin as an offset variable. Because preliminary data analysis suggested that the outcome of reproduction could be grouped into two major patterns, i.e., HB \& OB and WB \& MG, we fitted a separate model for each patterned group. The model included pollination treatment, the distance to the nearest male tree, and the directional diversity of nearby males as fixed effects, and plant individual as a random effect. For daytime and night-time hand pollination treatments, we fitted a GLM with a logarithmic link function and a Poisson error distribution. The number of mature seeds per capsule, the number of capsules per catkin, and pollination treatment were used as the response variable, an offset, and a fixed effect, respectively. Estimation of marginal (model-adjusted) means and SEs as well as pairwise comparisons of the estimates were performed using the "emmeans" package in $\mathrm{R}$ (Searle et al. 1980; Lenth et al. 2020).

Germination rate was compared among four pollination treatments (wind/diurnal/nocturnal/ natural) using a GLMM with a logit link function and a binomial error distribution. We considered the pollination treatment as a fixed effect and treated population and plant individual as nested random effects. Marginal means and SEs were estimated, and their pairwise comparisons were performed as described above.

Finally, we compared the time-course change in the proportion of viable pollen grains between different temperature conditions by fitting a GLMM with a logit link function and a binomial error distribution. We considered the days elapsed after anther dehiscence (0-4 days) and temperature condition (room/freezer) as fixed effects and plant as a random effect, together with an interaction term between days and temperature. All statistical analyses were performed using $\mathrm{R}$ version 3.6.2 (R Core Team 2019).

\section{RESULTS}

\section{FLOWER VISITORS}

While performing the pollination experiments, we observed various flower visitors on $S$. caprea both during daytime and night-time (Fig. 1). The diurnal flower visitors were solitary bees, honeybees, bumble-bee queens, flies, butterflies, and beetles. Solitary bees (Andrenidae and Colletidae) and honeybees were the most abundant visitors across the populations. They foraged for both pollen and nectar. Bumble-bee queens visited much less frequently and foraged primarily for nectar. Other visitors such as flies, butterflies, and beetles were observed only occasionally. The nocturnal visitors were predominantly settling moths, Noctuidae. Other settling moths such as Geometridae and Pterophoridae were also observed, but only rarely. These moths were all foraging on nectar. We occasionally found gall midges and lacewings on blooming catkins at night, but it was unclear what they had visited for. All these visitors were observed on both male and female catkins, except beetles that foraged only for pollen grains (Fig. $1 \mathrm{H})$.

\section{POLLINATION TREATMENTS}

In our study populations, seed set obtained under natural pollination was generally lower than those obtained by hand pollination (Fig. $2 ; \chi^{2}$ $=14.3, P=0.00016$, type-II Wald chi-square test). The population average of seed set ranged from 4 to $85 \%$ of hand pollination, which was highest for the population $\mathrm{OB}$, followed by $\mathrm{HB}, \mathrm{WB}$, and MG.

The results of the pollination treatments (wind/diurnal/nocturnal) differed from each other

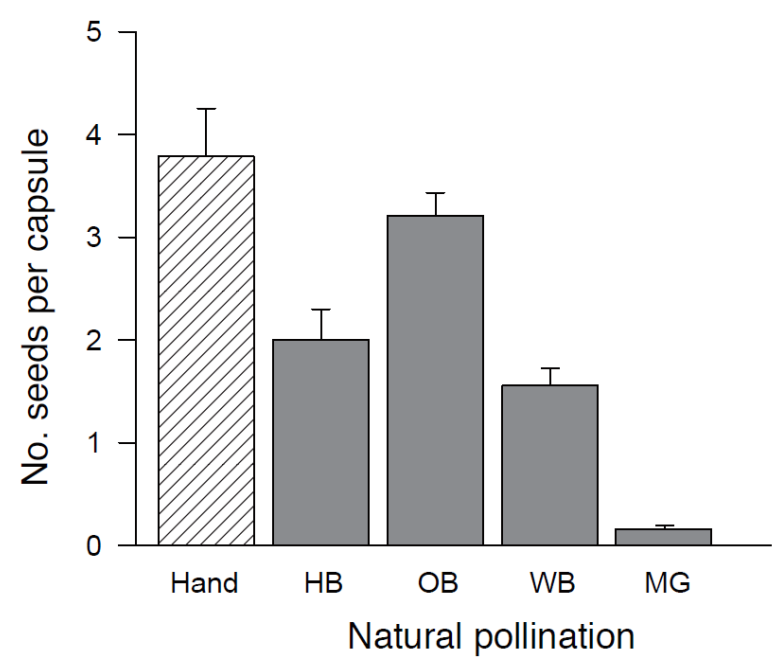

Figure 2. Seed production of Salix caprea in hand pollination and in natural pollination. Columns and bars indicate mean values and SEs. The data from daytime and night-time hand pollination are pooled, and those from natural pollination are shown separately for each population. 
in terms of how seed production was limited by local mate availability, i.e., the distance to the nearest male and the directional diversity of nearby males (Table 1, Fig. 3). In wind pollination treatments, the proportion of seed set was negatively correlated with the distance to the nearest male, and positively correlated with the directional diversity of nearby males (Table 1 ). Females produced very few seeds when they were more than $100 \mathrm{~m}$ away from the closest males (Fig.

\section{A) Wind pollination}

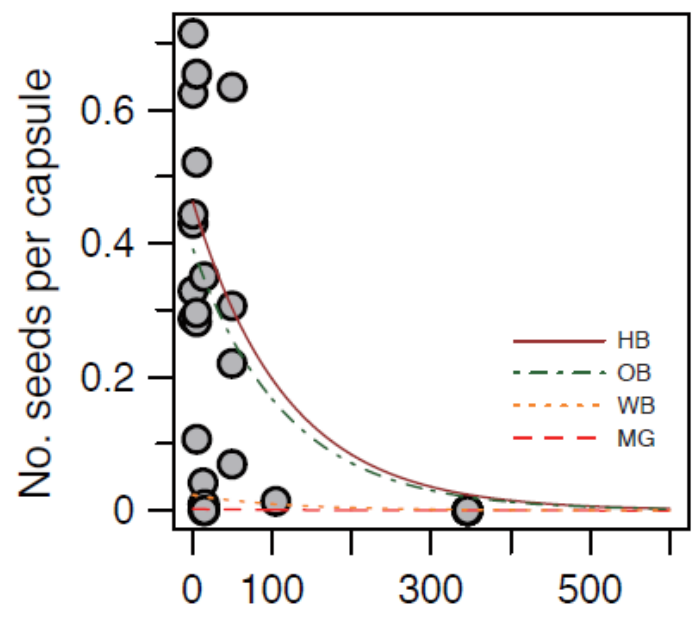

Distance to nearest male $(\mathrm{m})$

C) Diurnal pollination

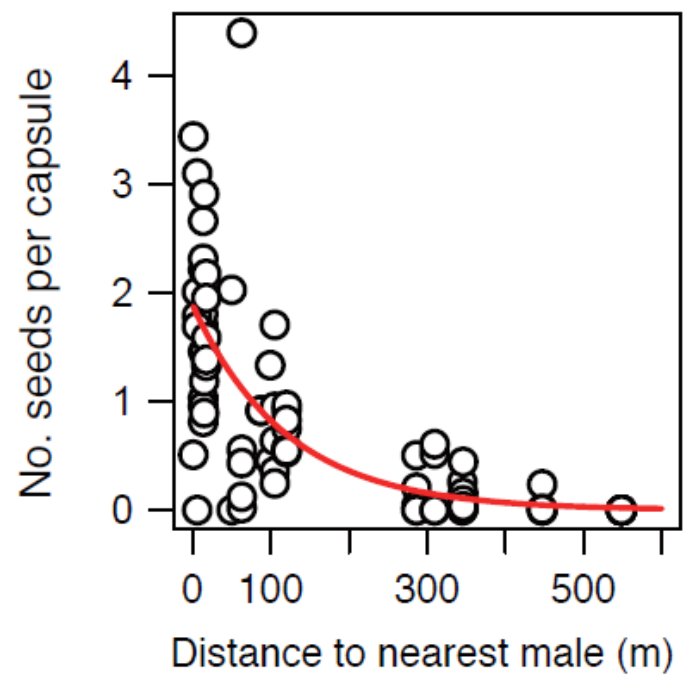

3A). In addition, females produced more seeds when nearby males were distributed in more diverse directions (Fig. 3B). However, these trends greatly varied among populations, as suggested by the large estimated standard deviation for the random effect, i.e., population (Table 1). In populations $\mathrm{WB}$ and $\mathrm{MG}$, females produced few seeds even when male trees were close (Fig. 3A) or when they were surrounded from various directions by males (Fig. 3B).

\section{B) Wind pollination}

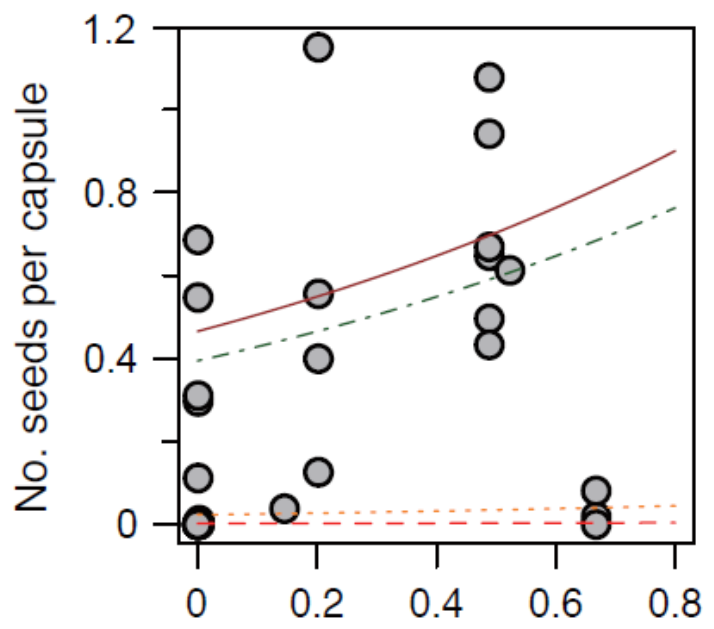

Directional diversity of nearby males
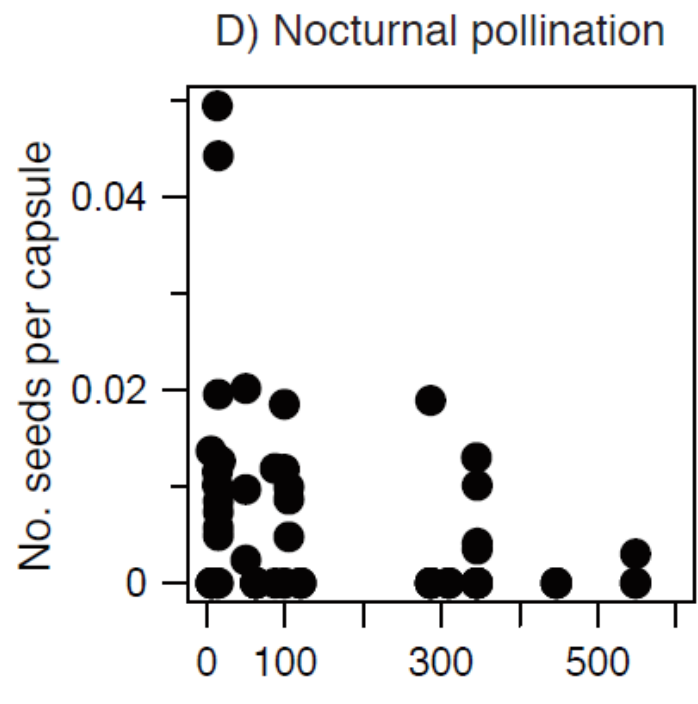

Distance to nearest male $(\mathrm{m})$

Figure 3. Effects of local mate availability on seed set of Salix caprea in different pollination treatments, showing the relationships between the number of seeds per capsule and the distance to the nearest male (A: wind, C: diurnal, D: nocturnal) or the directional diversity of nearby male (B: wind). The regression curves are drawn based on the estimated fixed effects in those GLMMs (A: $P$ <0.001; B: $P$ <0.0001; C: $P<0.001$; $D$ : $P$ = 0.14, type II Wald chi-square tests). The number of seeds was adjusted for the estimated random effect (plant) prior to data plotting. For wind pollination treatment, the number of seeds was further adjusted for the variance explained by (A) the directional diversity of nearby males or (B) the distance to the nearest male, and the regression curves were drawn separately for four populations by using the estimated random effect (population). 
In diurnal pollination treatments, where both wind and diurnal insects could make contributions to seed set, the proportion of seed set was similarly negatively correlated with the distance to the nearest male (Table 1). However, females produced a significant number of seeds even when they were $300 \mathrm{~m}$ away from the closest males (Fig. 3C). Also, this trend did not vary among populations, as suggested by the exceedingly small standard deviation for the population (Table 1). No significant effect was detected for the directional diversity of nearby males on seed production. In the nocturnal pollination treatment where both wind and nocturnal insects could make contributions, the proportion of seed set was not affected by either index of local mate availability (Table 1). However, the overall level of seed set was much lower than those obtained by the other two pollination treatments (Fig. 3D).

The seed production in different pollination treatments could be grouped into two major patterns with respect to the relative importance of nocturnal and wind pollination (Fig. 4). In the first group (populations $\mathrm{HB}$ and $\mathrm{OB}$ ), wind pollination

A

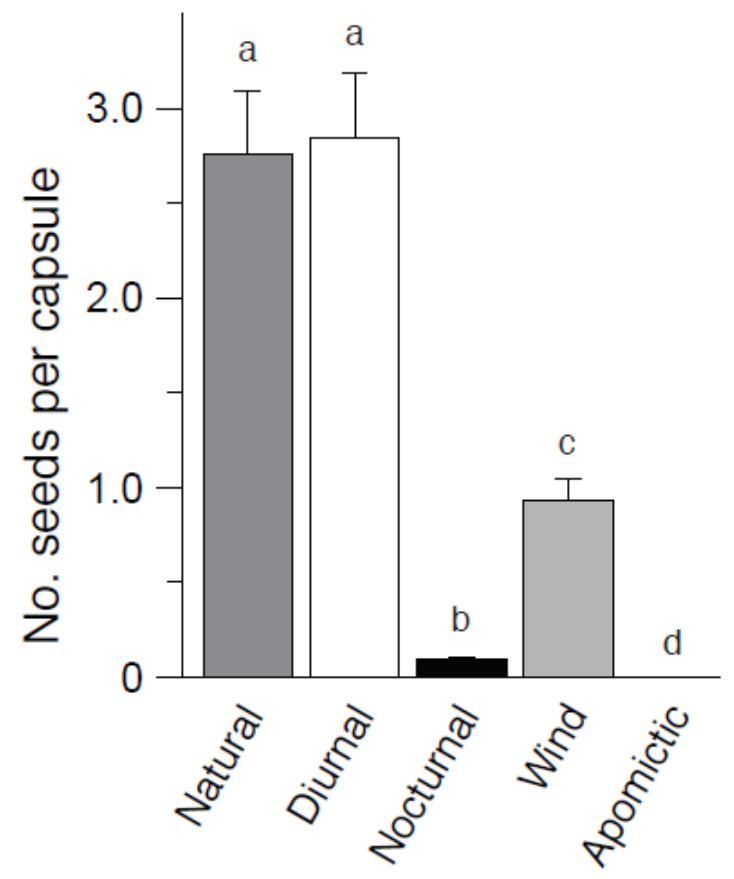

yielded significantly more seeds per capsule than nocturnal pollination (Fig. 4A). A contrasting pattern was observed in the second group (populations WB and MG), where wind pollination yielded significantly fewer seeds than nocturnal pollination (Fig. 4B). Natural pollination produced significantly more seeds than diurnal pollination only in the second group (Fig. 4B), although in both groups diurnal pollination accounted for most of the reproductive success. Irrespective of their relative importance, nocturnal and wind pollination always produced significantly more seeds than in apomictic reproduction where no seed was produced $(N=20$ catkins).

Finally, we detected no significant effect of day and night temperatures on the likelihood of successful fertilization. The proportion of seed set per capsule obtained in daytime and night-time hand pollination did not differ significantly from each other (daytime: marginal mean $\pm \mathrm{SE}=3.53 \pm$ 0.65 seeds/capsule, $N=18$ catkins, night-time: marginal mean $\pm \mathrm{SE}=3.44 \pm 0.70, N=13, Z=-0.095$, $P=0.92$, pairwise comparison of marginal means).

B

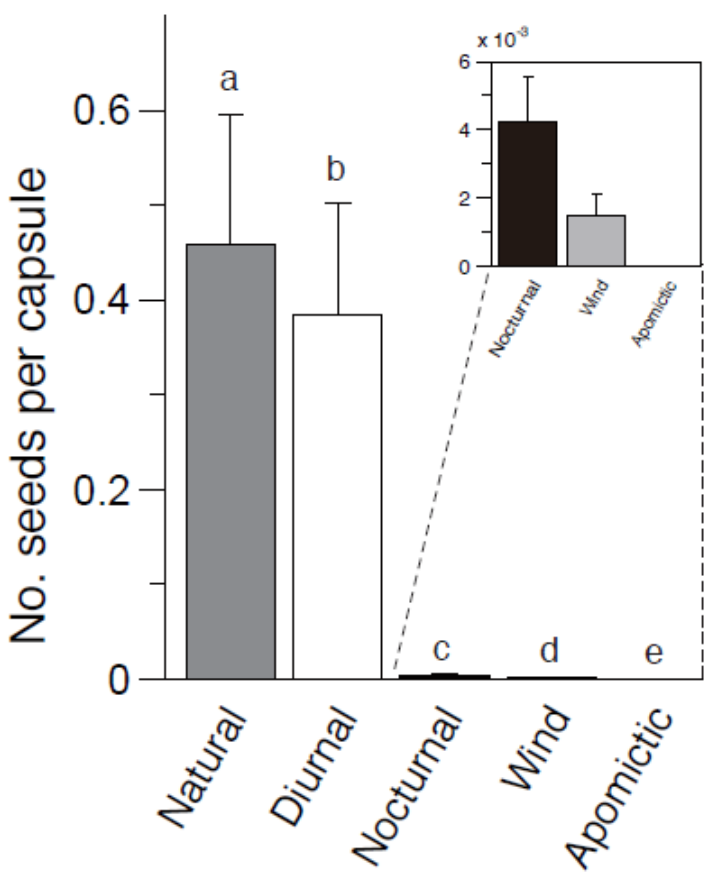

Figure 4. Seed set of Salix caprea in five pollination treatments. According to the patterns obtained, the data are divided into two groups of populations, i.e., (A) HB \& OB and (B) WB \& MG. Columns and bars indicate marginal (model-adjusted) means and SEs of the back-transformed proportions of seed set per capsule. The difference of means was tested for each pair of treatments. Means with shared letters are not significantly different at the 0.05 level after adjusted by Tukey correction. The inset graph magnifies the seed set axis to highlight the difference between nocturnal and wind pollination. 
Table 2. Seed germination rate of Salix caprea in different pollination treatments. Marginal (model-adjusted) mean values indicate the back-transformed proportions of germinated seeds per replicate. The right-half is a matrix representation of tests for difference of means in pairwise comparisons. Tukey-adjusted $P$ values are shown in parentheses.

\begin{tabular}{lllllll}
\hline & \multicolumn{2}{l}{ Estimated marginal mean and SE } & \multicolumn{2}{l}{$\begin{array}{l}\text { Difference of means and Tukey-adjusted } P \text { value } \\
\text { in pairwise comparison }\end{array}$} \\
\hline Treatment & Germination & SE & $N$ (replicates) & Diurnal & Nocturnal & Natural \\
Wind & 0,47 & 0,081 & 5 & $0.0078(P>0.99)$ & $0.0081(P>0.99)$ & $-0.073(P=0.55)$ \\
Diurnal & 0,46 & 0,068 & 17 & & $0.00038(P>0.99)$ & $-0.081(P=0.13)$ \\
Nocturnal & 0,46 & 0,079 & 13 & & $-0.081(P=0.46)$ \\
\hline
\end{tabular}

\section{GERMINATION RATE}

Although most viable seeds of $S$. caprea germinated within three days after sowing, we used the number of germinated seeds after six days of sowing. Approximately half of the seeds sown germinated in each of the four pollination treatments (wind/diurnal/nocturnal/natural), and no statistically significant differences were detected (Table 2).

\section{POLLEN LONGEVITY}

The proportion of viable pollen at the time of release from the anthers was approximately 60\%, from which it decreased significantly with time until day four (Fig. 5; $\chi^{2}=1747.1, P<0.0001$, typeII Wald chi-square test). The decline was slightly but significantly less for grains stored in the freezer than at room temperature, as suggested by the significant interaction between days and temperature $\left(\chi^{2}=79.1, P<0.0001\right.$, type-II Wald chisquare test).

\section{THE ONSET OF ANTHESIS}

Salix caprea has dusk-opening flowers-more than $70 \%$ of the flowers on the examined male catkins opened between 16:00 and 21:00 h, with the peak time occurring from 17:00 to 18:00 h (Fig. 6). There was another small peak occurring from 8:00 to $9: 00 \mathrm{~h}$ in the next morning, although $92 \%$ of the flowers had already opened before this period.

\section{Discussion}

For early blooming species such as $S$. caprea, wind pollination has an apparent advantage compared to insect pollination. The weather conditions during early springtime in Germany are characterized by occasional low temperatures - the night temperatures could be well below freezing (e.g., Vitasse \& Rebetez 2018).
Wind pollination is likely to be less affected by such low temperatures than insect pollination (Regal 1982; Culley et al. 2002). Given this advantage of wind pollination in low-temperature environments, it is not immediately obvious why S. caprea employs insect pollination at the same time. Previous authors have hypothesized that ambophily has evolved because environments vary spatially in conditions that favor either wind or animal pollination (Culley et al. 2002). Our findings support this hypothesis by showing that wind pollination is strongly limited by the distance to nearby males, the diversity of directions they are relative to the female, and site openness, etc., while insect pollination is not limited by these factors. Thus, insect pollination could compensate for the deficiency of wind pollination when individuals are distant from potential mates, positioned to have mates in similar directions, or surrounded by forest trees. In the case of iteroparous species, temporal fluctuation could be overcome by an adaptation to the most frequent weather condition, but spatial factors are more problematic because they are not likely to change from year to year. Salix caprea seems to mitigate such spatial variability by combining wind and animal pollination.

LIMITATIONS AND COMPENSATORY RELATIONSHIPS AMONG THE THREE POLLINATION MODES

The levels of seed set from natural pollination of $S$. caprea were generally lower than those from artificial pollination (Fig. 2), suggesting pollen limitation in the investigated trees. This seems plausible, given that the species is dioecious and thus pollen-vector dependent, blooms in early spring when temperatures are relatively low, and is sparsely distributed as a light-demanding, pioneering plant. The results support the view that 


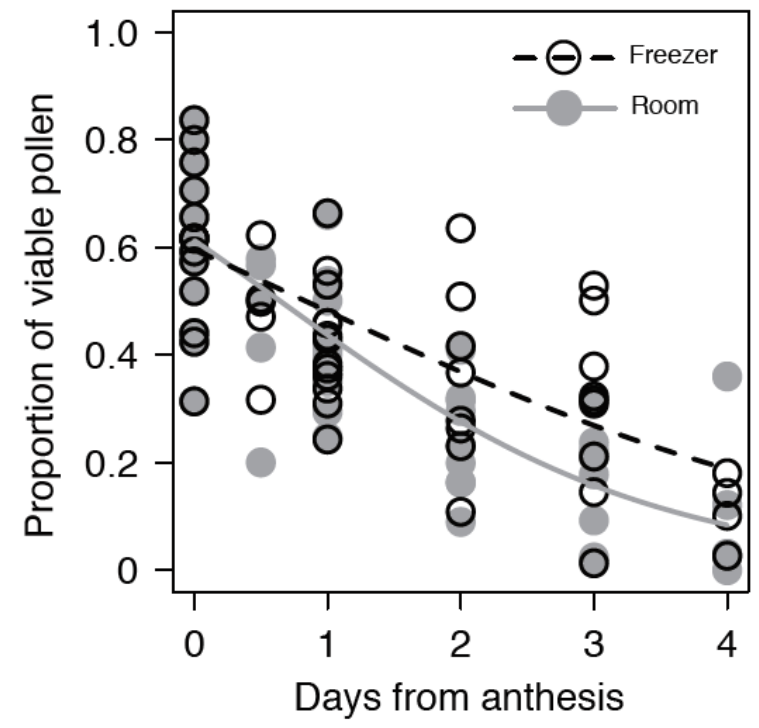

Figure 5. Pollen longevity of Salix caprea under two temperature conditions, showing the relationships between the proportion of viable pollen and days elapsed since pollen release from anthers. Because the model fitted to the pooled data suggested a significant difference between the two temperature conditions $\left(\chi^{2}=\right.$ 39.1, $P<0.0001$, type-II Wald chi-square test) with a significant interaction between days and temperature $\left(\chi^{2}\right.$ $=79.1, P<0.0001$, type-II Wald chi-square test), the regression curves are drawn separately for the two temperature conditions based on the estimated fixed effects. The number of seeds was adjusted for the estimated random effect (plant) prior to data plotting.

all three pollination modes are used simultaneously to ensure reproduction.

Our results indicate that animal pollination can compensate for the deficiency of wind pollination in plants whose local mate availability is limited. Wind and insect pollination differed in how they were affected by local mate availability (Fig. 3). Seed production via wind pollination rapidly declined with increasing distance to the nearest male. On the other hand, diurnal and nocturnal pollination, in which contributions of insects as well as the wind are included, produced a significant number of seeds even when males were not available in close range. This suggests that insects delivered pollen to stigmas over longer distances. It has long been known that wind pollination is usually not as effective as animal pollination when inter-individual distances are large (reviewed by Regal 1982). This is because the air-borne pollen rain from a single plant dilutes rapidly-probably as the inverse square of the distance - and because stigmatic surfaces are tiny targets. For S. caprea, whose pollen diameter is relatively large and tree height is relatively short (mostly $<10 \mathrm{~m}$ ), the decline may be particularly steep. In the dioecious herb Amaranthus with similar-sized pollen $(\sim 20 \mu \mathrm{m})$, fertility declined rapidly from $81 \%$ to $12 \%$ when inter-plant distance increased from less than one meter to several meters (Lemen 1980). In addition to this, seed set from wind pollination in S. caprea was positively correlated with the directional diversity of surrounding mates, while no such trend was observed in diurnal and nocturnal pollination. This result probably reflects the strong directionality of the wind in the same terrain (Allen et al. 1989), while insects tend to fly in more diverse directions. To our knowledge, this is the first demonstration that animal pollination could potentially surpass wind pollination in situations where available pollen donors are clustered in narrow directions from the pollen recipients.

Moreover, the relationships between seed set and local mate availability in wind pollination varied significantly among populations (Fig. 3). Specifically, in populations WB and MG, females did not produce seeds via wind pollination even when males were close or distributed in diverse directions. This suggests the existence of some unknown habitat-specific factors that limit wind pollination. Such spatial variation was not observed for diurnal and nocturnal pollination treatments where contributions from insects were involved. Considering that MG was located in closed forest habitat, it seems likely that the surrounding tall trees and their leaves-especially those of evergreen conifers - provided a physical barrier to pollen dispersal by wind (Millerón et al. 2012). On the other hand, it is not clear why wind pollination was not effective in WB, which was located in open riverbank habitat. It has been reported that wind pollination is negatively correlated with precipitation and species richness (Rech et al. 2016). However, these factors do not seem to apply, because WB was not far apart from the other populations, either in distance or elevation, and also because it was dominated by deciduous trees that had few or no leaves during the flowering season of $S$. caprea. In riverbank populations where plants are normally distributed in a line along the river, wind pollination may perform poorly unless the local wind direction is parallel to the river. It may also be possible that 


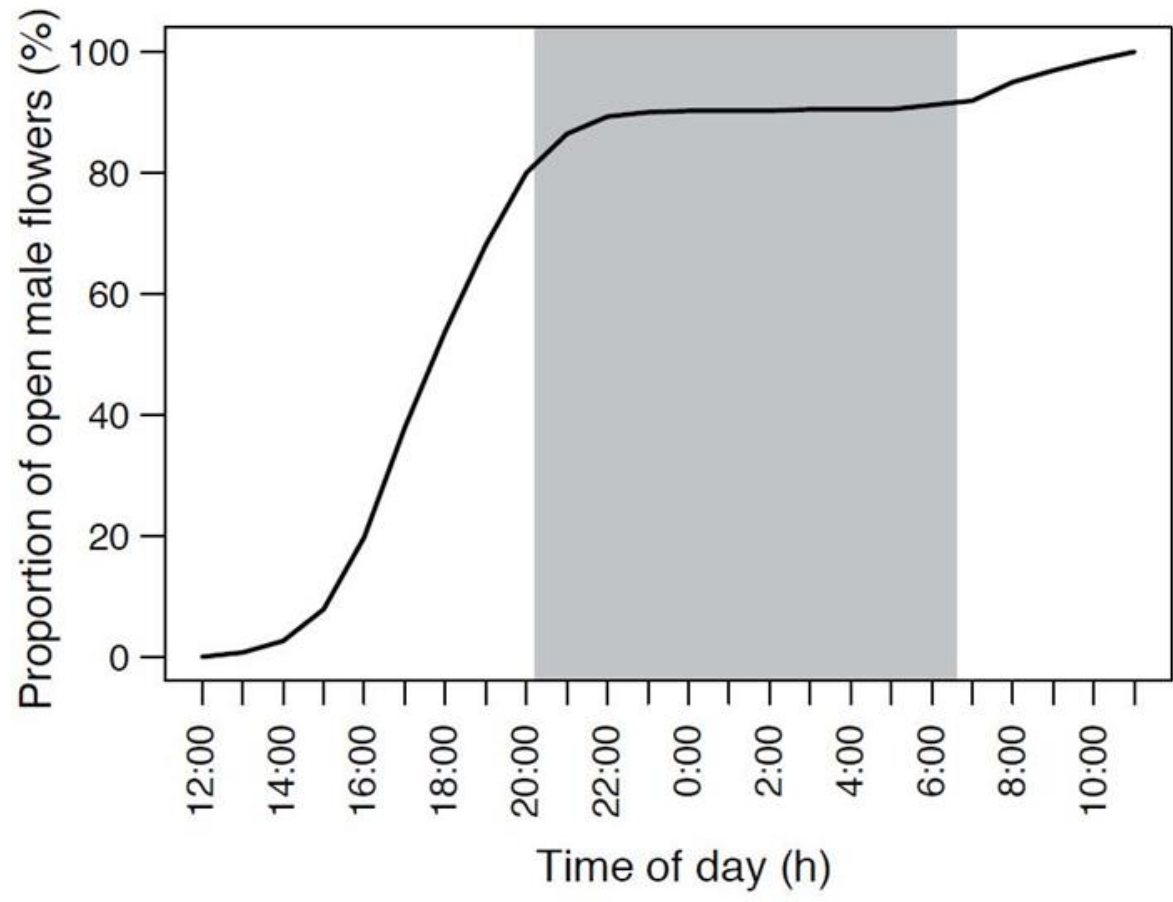

FIGURE 6. Timing of anthesis in 210 flowers from five male catkins of Salix caprea. Data from $\mathrm{HB}(\mathrm{N}=3$ catkins $)$ and $M G$ $(N=2)$ populations. Shaded area indicates the average nocturnal period during the study. wind pollination was limited by the average height of male trees in WB. These factors were not evaluated in our study and could be addressed in future research.

As a consequence of such habitat effects, the relative importance of nocturnal and wind pollination varied markedly among populations (Fig. 4). In $\mathrm{HB}$ and $\mathrm{OB}$, where wind pollination was effective, the contribution of nocturnal pollination was less than $13 \%$ of that of wind pollination, indicating that moth pollination was redundant in these populations. On the other hand, in WB and MG where wind pollination was ineffective, the contribution of nocturnal pollination was 2.8 times greater than that of wind pollination. In the latter two populations, natural pollination produced slightly but significantly more seeds than diurnal pollination. In other words, moth pollination worked complementarily with bee pollination in compensating for the lack of wind pollination. Even such a small increase may benefit plants, given that pollen limitation seems common in $S$. caprea, and also that such spatial disadvantages are unlikely to disappear over time. It has been suggested theoretically that the relative fitness of a plant producing a few seeds would become quite high when population mean fitness is low (Benkman 2013). The reason the contribution by moths was much lower than that by bees is unclear, but may be attributed to their less frequent visits (Jürgens et al. 2014), and also due to their low effectiveness in pollen removal/deposition (Miyake \& Yahara 1998).

Diurnal and nocturnal pollination did not show a clear pattern of compensation at least with respect to spatial variation in the environment (Figs. 3, 4). On the other hand, moths may compensate for the deficiency of bee pollination when environmental factors, such as temperature, favour them to emerge from overwintering earlier than bees. For example, moth species photographed in Fig. 1 have been reported to be more active than the bee species during February (bees:moths = 73:1766), March (2596:7051), and April (8772:12554), respectively (observed number of adults per species; The Global Biodiversity Information Facility: www.gbif.org). This may indicate that moths are more dependable pollinators than bees during years with cold spring temperatures. If this is the case, in areas where wind pollination is ineffective (e.g., WB and MG), the attraction of moths may be important to counteract the scarcity of bees in cold seasons. Given that $S$. caprea switches floral scent profiles between day and night at the cost of producing different chemicals (Jürgens et al. 2014), such situations may not be rare in nature. 
Nocturnal pollination had a lower level of seed set than wind pollination in populations $\mathrm{HB}$ and OB (Fig. 4A). Considering that wind was an effective pollen vector in these habitats, the poor set of seed in nocturnal pollination seems to suggest that wind pollination occurred mostly during daytime. We cannot determine the exact cause of this, but it is possible that the general trend of low winds and high humidity at night prevented the pollen from being carried by the wind (Niklas 1985). For instance, in the area where WB was located, the average wind speed during April 2018 was slower at night (day: light breeze, mean $\pm \mathrm{SD}=3.2 \pm 1.6 \mathrm{~m} / \mathrm{s}$, night: light air, $2.1 \pm 0.85$ $\mathrm{m} / \mathrm{s}, N=30$ ), while the average humidity was higher (day: $51 \pm 12 \%$, night: $79 \pm 7.9 \%, N=30$ ) (www.worldweatheronline.com/wiebelsbachweather/hessen/de.aspx).

\section{SCHEDULE OPTIMIZATION IN THE TIMING OF ANTHESIS}

Although we only measured female function in terms of seed set, the fact that male flowers of $S$. caprea opened around sunset (Fig. 6) suggests that selection through male function is also operating. The brush-like catkins of $S$. caprea seem to be effective in mitigating phenotypic tradeoffs among pollen vectors. They allow the anthers and stigmas to touch the bodies of insects with different body morphologies. Furthermore, brush-like inflorescences are also good for pollination by wind because they allow the removal and deposition of pollen from any direction. On the other hand, such an open structure will make it easier for bees to remove large amounts of pollen at a single visit to a male catkin. This may make a big difference between bees and moths in their efficiency of pollen transfer. It has been pointed out that the more pollen a bee picks up from a flower, the larger portion of it is likely to be removed by grooming during transport (Harder \& Thomson 1989; Reynolds et al. 2009). In contrast to bees, moths do not groom off pollen, so they are expected to deliver a larger portion of pollen to stigmas. Therefore, while moth visitors are infrequent and probably do not pick up much pollen, pollen wastage in moths is considered to be lower than in bees. In such a condition, male flowers of $S$. caprea could maximize the total pollen transfer to conspecific stigmas when they open in the evening, through obtaining marginal fitness gain from more efficient, nocturnal moth pollinators. If male flowers open in the morning and allow frequent visits by diurnal bees, in contrast, few or no pollen will be left by the time nocturnal moths arrive. Wind pollination is also likely to waste much pollen during transport because it is not well directed towards stigmas (Regal 1982; Culley et al. 2002). Given that wind pollination occurred mostly during the daytime, the dusk-opening in S. caprea would also increase the chances of moths contributing to male fitness. Cold temperatures at night did not appear to reduce pollen longevity (Fig. 5). Even though females do not receive as much pollen at night, males likely get more directed pollen dispersal by moths. Such a "schedule optimization" of floral anthesis may be an effective way to maximize male fitness by reducing pollen loss during transport to stigmas (Minnaar et al. 2019). Our results are in agreement with other authors that have made similar suggestions on the significance of the timing of anthesis in generalist flowers (Miyake \& Yahara 1998, 1999; Muchhala et al. 2008). Future studies could investigate whether female receptivity varies between day and night in accordance with the change in pollen transfer efficiency.

Nocturnal anthesis of S. caprea seemed to have no effect on its female reproductive success. In our daytime and night-time hand-pollination treatments, cold temperatures at night did not reduce seed set. In addition, we found no evidence that nocturnal moths were more efficient at fertilizing ovules than diurnal bees-the seed germination rate did not differ between diurnal and nocturnal pollination (Table 2). This may reflect that bees and moths carried pollen just as far, in contrary to previous reports that lepidopterans often disperse pollen farther than bees (Schmitt 1980; Miyake \& Yahara 1998; Barthelmess et al. 2006; Skogen et al. 2019). However, one should note that the germination rate did not differ even for wind pollination (Table 2) where mating was likely to occur within a closer range (Fig. 3). The lack of difference in germination rates despite the difference in mating distance may indicate that natural populations of $S$. caprea are not genetically structured. Considering that the seeds of $S$. caprea are tiny and equipped with a pappus (hair-like outgrowths that aid the wind dispersal of seeds), these seeds may travel far and make the genetic structure within local 
populations very weak (Loveless \& Hamrick 1984). Indeed, geostatistical models based on seed trapping and parentage analysis have confirmed long dispersal distances of $500-800 \mathrm{~m}$ in S. caprea (Tiebel et al. 2019). Thus, even if nocturnal moths carry pollen farther than diurnal bees (Miyake \& Yahara 1998; Barthelmess et al. 2006; Skogen et al. 2019), it is unlikely that they have a strong impact on the seed quality in S. caprea populations.

In conclusion, flowers of $S$. caprea seem to minimize the risk of reproductive failure by combining wind and insect pollination that are differently affected by spatial and temporal variation. In particular, we discovered that insect pollination could outperform wind pollination in situations where nearby pollen donors are few or all positioned in the same direction from the recipients. Future studies will need to examine how such a pattern is commonly found between wind and animal pollination. Nocturnal pollination by moths worked complementarily

\section{ACKNOWLEDGEMENTS}

We are grateful to Taina Witt for locating field populations of Salix, as well as valuable discussions on logistics and experimental design. We are also grateful to Chieko Koshida for her patient assistance in our field work, Makiko Sekine for shipping fruit-protecting paper bags from Japan, and Hessisches Landesamt für Bodenmanagement und Geoinformation for providing us the digital orthophotos of our field sites. Finally, we thank the reviewers, especially Nathan Muchhala for his careful and insightful comments on our manuscript. This work was supported by a JSPS Grants-in-Aid for Scientific Research (KAKENHI no. 15KK0249) to K.O.

\section{APPENDICES}

Additional supporting information may be found in the online version of this article:

Appendix I. Distribution of focal female trees and the surrounding male trees of Salix caprea in four study populations (A: Heubach, B: Ohlebach, C: Wiebelsbach, D: MümlingGrumbach. Photos by Hessisches Landesamt für Bodenmanagement und Geoinformation.

\section{REFERENCES}

Aigner PA (2001) Optimality modeling and fitness tradeoffs: when should plants become pollinator specialists? Oikos 95:177-184. https://doi.org/10.1034/j.16000706.2001.950121.x with diurnal bee pollination in compensating for the lack of wind pollination, which would be especially important under cold temperatures during early spring to which the activity of moths is less susceptible than diurnal bees. In addition, $S$. caprea opens its flowers in the evening, which would minimize the wastage of pollen by diurnal bees and allow it to be transferred more efficiently by moths and, consequently, maximize the amount of pollen delivered to conspecific stigmas. The acquisition of a mixed pollination system that combines multiple pollen vectors working in different environments in a way that minimizes their potential conflicts may partly explain the fact that $S$. caprea is one of the few willow species that has successfully invaded closed habitats such as forest understories (Enescu et al. 2016). Thus, $S$. caprea may have achieved "adaptive generalization" for diverse pollen vectors, in the sense that they increase reproductive assurance without suffering from fitness losses due to conflicts among vectors.

Allen MF, Hipps LE, Wooldridge GL (1989) Wind dispersal and subsequent establishment of VA mycorrhizal fungi across a successional arid landscape. Landscape Ecology 2:165-171. https://doi.org/10.1007/BF00126016

Amorim FW, Galetto L, Sazima M (2013) Beyond the pollination syndrome: nectar ecology and the role of diurnal and nocturnal pollinators in the reproductive success of Inga sessilis (Fabaceae). Plant Biology 15:317327. https://doi.org/10.1111/j.1438-8677.2012.00643.x

Barthelmess EL, Richards CM, McCauley DE (2006) Relative effects of nocturnal vs diurnal pollinators and distance on gene flow in small Silene alba populations. New Phytologist 169:689-698. https://doi.org/10.1111/j.14698137.2005.01580.x

Benkman CW (2013) Biotic interaction strength and the intensity of selection. Ecology Letters 16:1054-1060. https://doi.org/10.1111/ele.12138

Costa ACG, Machado IC (2012) Flowering dynamics and pollination system of the sedge Rhynchospora ciliata (Vahl) Kükenth (Cyperaceae): Does ambophily enhance its reproductive success? Plant Biol 14:881-887. https://doi.org/10.1111/j.1438-8677.2012.00574.x

Culley TM, Weller SG, Sakai AK (2002) The evolution of wind pollination in angiosperms. Trends in Ecology \& Evolution 17:361-369

Dellinger AS, Scheer LM, Artuso S, et al (2019) Bimodal pollination systems in Andean Melastomataceae involving birds, bats, and rodents. American Naturalist 194:104-116. https://doi.org/10.1086/703517

Dötterl S, Glück U, Jürgens A, et al (2014) Floral reward, advertisement and attractiveness to honey bees in 
dioecious Salix caprea. PLoS One 9:1-11. https://doi.org/10.1371/journal.pone.0093421

Dötterl S, Jahreiß K, Jhumur US, Jürgens A (2012) Temporal variation of flower scent in Silene otites (Caryophyllaceae): A species with a mixed pollination system. Botanical Journal of the Linnean Society 169:447-460. https://doi.org/10.1111/j.1095-8339.2012.01239.x

Duan YW, Zhang TF, He YP, Liu JQ (2009) Insect and wind pollination of an alpine biennial Aconitum gymnandrum (Ranunculaceae). Plant Biology 11:796-802. https://doi.org/10.1111/j.1438-8677.2009.00195.x

Enescu CM, Houston Durrant T, Rigo D de, Caudullo G (2016) Salix caprea in Europe: distribution, habitat, usage and threats. In: European Atlas of Forest Tree Species. Publication Office of the EU, Luxembourg

Fleming TH, Sahley CT, Holland JN, et al (2001) Sonoran Desert columnar cacti and the evolution of generalized pollination systems. Ecological Monographs 71:511-530. https://doi.org/10.1890/00129615(2001)071[0511:SDCCAT]2.0.CO;2

Gong YB, Yang M, Vamosi JC, et al (2016) Wind or insect pollination? Ambophily in a subtropical gymnosperm Gnetum parvifolium (Gnetales). Plant Species Biology 31:272-279. https://doi.org/10.1111/1442-1984.12112

Goodwillie C (1999) Wind pollination and reproductive assurance in Linanthus parviflorus (Polemoniaceae), a selfincompatible annual. American Journal of Botany 86:948954. https://doi.org/10.2307/2656611

Grant V, Grant KA (1965) Flower pollination in the Phlox Family. Columbia University Press

Harder LD, Thomson JD (1989) Evolutionary options for maximizing pollen dispersal of animal-pollinated plants. American Naturalist 133:323-344

Johnson SD, Hargreaves AL, Brown M (2006) Dark, bittertasting nectar functions as a filter of flower visitors in a bird-pollinated plant. Ecology 87:2709-2716

Johnson SD, Steiner KE (2000) Generalization versus specialization in plant pollination systems. Trends in Ecology \& Evolution 15:140-143

Jürgens A, Glück U, Aas G, Dötterl S (2014) Diel fragrance pattern correlates with olfactory preferences of diurnal and nocturnal flower visitors in Salix caprea (Salicaceae). Botanical Journal of the Linnean Society 175:624-640. https://doi.org/10.1111/boj.12183

Kay QON (1985) Nectar from willow catkins as a food source for blue tits. Bird Study 32:40-44. https://doi.org/10.1080/00063658509476853

Lemen C (1980) Allocation of reproductive effort to the male and female strategies in wind-pollinated plants. Oecologia 159:156-159

Lenth R, Singmann H, Love J, et al (2020) Package 'emmeans.' R Package version 1.15-15 34:216-221
Loveless MD, Hamrick JL (1984) Ecological determinants of genetic structure in plant populations. Annual Review of Ecology and Systematics 15:65-95. https://doi.org/10.1146/annurev.es.15.110184.000433

Martén-Rodríguez S, Fenster CB (2010) Pollen limitation and reproductive assurance in Antillean Gesnerieae: a specialist vs. generalist comparison. Ecology 91:155-165. https://doi.org/10.1890/08-2115.1

Millerón M, López de Heredia U, Lorenzo Z, et al (2012) Effect of canopy closure on pollen dispersal in a windpollinated species (Fagus sylvatica L.). Plant Ecology 213:1715-1728. https:/doi.org/10.1007/s11258-012-0125-2

Minnaar C, Anderson B, De Jager ML, Karron JD (2019) Plant-pollinator interactions along the pathway to paternity. Annals of Botany 123:225-245. https://doi.org/10.1093/aob/mcy167

Miyake T, Yahara T (1998) Why does the flower of Lonicera japonica open at dusk? Canadian Journal of Botany 76:1806-1811

Miyake T, Yahara T (1999) Theoretical evaluation of pollen transfer by diurnal and nocturnal pollinators: when should a flower open? Oikos 2:233-240

Muchhala N, Thomson JD (2010) Fur versus feathers: pollen delivery by bats and hummingbirds and consequences for pollen production. American Naturalist 175:717-726. https://doi.org/10.1086/652473

Muchhala N, Caiza A, Vizuete JC, Thomson JD (2008) A generalized pollination system in the tropics: bats, birds and Aphelandra acanthus. Annals of Botany 103:1481-1487. https://doi.org/10.1093/aob/mcn260

Niklas KJ (1985) The aerodynamics of wind pollination. Botanical Review 51:328-386. https://doi.org/10.1007/BF02861079

Perdereau AC, Kelleher CT, Douglas GC, Hodkinson TR (2014) High levels of gene flow and genetic diversity in Irish populations of Salix caprea L. inferred from chloroplast and nuclear SSR markers. BMC Plant Biology 14:1-12. https://doi.org/10.1186/s12870-014-0202-x

Pewsey A, Neuhauser M, Ruxton GD (2013) Circular statistics in R. Oxford University Press

Popova E V, Kim DH, Han SH, et al (2012) Narrowing of the critical hydration window for cryopreservation of Salix caprea seeds following ageing and a reduction in vigour. Cryo-Letters 33:220-231

Rech AR, Dalsgaard B, Sandel B, et al (2016) The macroecology of animal versus wind pollination: ecological factors are more important than historical climate stability. Plant Ecology \& Diversity 9:253-262. https://doi.org/10.1080/17550874.2016.1207722

Regal PJ (1982) Pollination by wind and animals: ecology of geographic patterns. Annual Review of Ecology and 
Systematics

13:497-524

https://doi.org/10.1146/annurev.es.13.110182.002433

Reynolds RJ, Westbrook MJ, Rohde AS, et al (2009) Pollinator specialization and pollination syndromes of three related North American Silene. Ecology 90:20772087. https://doi.org/10.1890/08-1141.1

Rodriguez-Riano T, Dafni A (2000) A new procedure to assess pollen viability. Sexual Plant Reproduction 12:241244. https://doi.org/10.1007/s004970050008

Schmitt J (1980) Pollinator foraging behavior and gene dispersal in Senecio (Compositae). Evolution 34:934-943

Searle SR, Speed FM, Milliken GA (1980) Population marginal means in the linear model: an alternative to least squares means. American Statistician 34:216-221. https://doi.org/10.1080/00031305.1980.10483031

Skogen KA, Overson RP, Hilpman ET, Fant JB (2019) Hawkmoth pollination facilitates long-distance pollen dispersal and reduces isolation across a gradient of land- use change. Annals of the Missouri Botanical Garden 104:495-511. https://doi.org/10.3417/2019475

Stebbins GL (1970) Adaptive radiation of reproductive characteristics in angiosperms, I: pollination mechanisms. Annual Review of Ecology and Systematics 1:307-326. https://doi.org/10.1146/annurev.es.01.110170.001515

Thomson JD, Wilson P, Valenzuela M, Malzone M (2000) Pollen presentation and pollination syndromes, with special reference to Penstemon. Plant Species Biology 15:11-29. https://doi.org/10.1046/j.1442-1984.2000.00026.x

Tiebel K, Leinemann L, Hosius B, et al (2019) Seed dispersal capacity of Salix caprea L. assessed by seed trapping and parentage analysis. European Journal of Forest Research 138:495-511. https://doi.org/10.1007/s10342-019-01186-2

Vitasse Y, Rebetez M (2018) Unprecedented risk of spring frost damage in Switzerland and Germany in 2017. Climatic Change 149:233-246. 